BMJ Paediatrics Open

\title{
Population-based study of influenza and invasive meningococcal disease among Greek children during the COVID-19 pandemic
}

Danai Ktena (D , , Eleni Kourkouni, ${ }^{2}$ Flora Kontopidou, ${ }^{3}$ Kassiani Gkolfinopoulou, ${ }^{4}$ Kalliopi Papadima, ${ }^{5}$ Theano Georgakopoulou, ${ }^{6}$ Ioanna Magaziotou, ${ }^{6}$ Anastasia Andreopoulou, ${ }^{5}$ Georgina Tzanakaki, ${ }^{7}$ Theoklis Zaoutis, ${ }^{8,9}$ Vassiliki Papaevangelou ${ }^{1}$

To cite: Ktena D, Kourkouni E, Kontopidou F, et al. Populationbased study of influenza and invasive meningococcal disease among Greek children during the COVID-19 pandemic. BMJ Paediatrics Open 2022;6:e001391. doi:10.1136/ bmjpo-2021-001391

- Additional supplemental material is published online only. To view, please visit the journal online (http://dx.doi.org/ 10.1136/bmjpo-2021-001391).

TZ and VP contributed equally.

Received 21 December 2021 Accepted 21 January 2022

Check for updates

C Author(s) (or their employer(s)) 2022. Re-use permitted under CC BY-NC. No commercial re-use. See rights and permissions. Published by BMJ.

For numbered affiliations see end of article.

Correspondence to Dr Vassiliki Papaevangelou; vpapaev@med.uoa.gr

\section{ABSTRACT}

Background Aiming to the containment of the coronavirus disease 2019 (COVID-19) pandemic, governments worldwide have implemented a series of non-pharmaceutical interventions. Many of them and especially school closures have impacted the circulation of multiple airborne pathogens among children and adolescents. This study investigates the incidence of influenza and invasive meningococcal disease among children aged 0-14 years in Greece during the COVID-19 pandemic

Methods Data regarding the number of influenza-like illness cases, influenza-related paediatric intensive care unit (PICU) admissions and invasive meningococcal disease cases among children $0-14$ years old were obtained from the National Public Health Organization. The incidence of the two diseases during the COVID-19 pandemic period (2020/2021) was compared with that of the six preceding seasons (2014-2019).

Results A notable decrease was observed in both influenza and invasive meningococcal disease cases during the period 2020/2021 compared with the years 2014-2019. The mean annual rate of influenza-like illness cases and influenza-related PICU admissions in children $0-14$ years old has reduced by $66.9 \%$ and $100 \%$, respectively, while the mean annual invasive meningococcal disease rate has declined by $70 \%$. Both weekly influenza-like illness and monthly invasive meningococcal disease rates were significantly decreased. Conclusions The activity of influenza and invasive meningococcal disease in the children and adolescents of Greece has decreased during the COVID-19 pandemic period. Reduced transmission is likely related to the public health measures that were implemented to control the pandemic. The value of these measures may have relevance to the future management of influenza or invasive meningococcal disease epidemics.

\section{INTRODUCTION}

In December 2019, severe acute respiratory syndrome coronavirus 2 (SARS-CoV-2), a novel coronavirus, which causes coronavirus disease 2019 (COVID-19), emerged in

\section{What is known about the subject?}

Influenza and other viral infections increase the risk of invasive meningococcal disease.

- The past winter raised concern regarding the cocirculation of SARS-CoV-2 and influenza and the possible role the former might play as a risk factor for invasive meningococcal disease.

- The activity of many respiratory pathogens remained low during the season 2020/2021.

\section{What this study adds?}

The incidence of influenza in children aged 0-14 years has decreased significantly in the period 2020/2021 compared with the preceding seasons.

- Monthly invasive meningococcal disease rates in children under 14 years of age have also declined since March 2020 compared with the previous 6 years.

- The decrease of influenza and invasive meningococcal disease cases in children temporally coincides with the implementation of several interventions used for the control of the COVID-19 pandemic.

Wuhan, China. ${ }^{1}$ The disease spread rapidly and on 11 March 2020 WHO declared a COVID-19 pandemic. $^{2}$ Since then, more than 435 million confirmed cases have been reported globally, 2 million of which in Greece. ${ }^{3}$ COVID-19 is transmitted from person to person mainly via respiratory droplets, including aerosols, as well as direct contact. ${ }^{4}$ To contain viral transmission a series of non-pharmaceutical public health measures, such as social distancing, use of face masks, promotion of increased hand hygiene, lockdown, curfew, school closures, isolation of confirmed cases and quarantine of exposed subjects, have been 
implemented since March 2020. Due to their broad implementation, these measures potentially impact the transmission of other infectious diseases that spread via the respiratory route as well.

Seasonal influenza is a common cause of respiratory disease, linked to increased rates of hospitalisations, in both children and adults. ${ }^{5}$ Influenza virus is transmitted via respiratory droplets, aerosols and through contact with infected individuals or contaminated fomites. In temperate regions, epidemics occur every winter and are associated with increased morbidity and mortality. ${ }^{6}$ The expected influenza peak during the winter months of 2020 and the co-circulation with SARS-CoV-2 caused worldwide concern, regarding the consequential overwhelming of healthcare systems and therefore campaigns promoting influenza vaccination, both among adults and children, were held in many countries. In Greece, influenza vaccination for children according to the National Immunization Program (NIP), is recommended only for those at high risk. ${ }^{7}$ However, the incidence of influenza during the endemic periods of both 2019-2020 and 2020-2021 remained notably low, not only in Europe, but also globally. ${ }^{8-10}$

Considering then, the known role of influenza infection as a risk factor for invasive meningococcal disease (IMD), one may postulate a concomitant decrease of the IMD incidence during the COVID-19 pandemic. ${ }^{11}$ IMD usually presents as meningitis or septicaemia and mainly affects children younger than 2 years old and adolescents. It is caused by Neisseria meningitidis, which is transmitted from person to person through respiratory droplets from infected patients or carriers. ${ }^{12}$ The rate of $N$. meningitidis asymptomatic carriage shows an increasing trend through childhood from $4.5 \%$ in infants to a peak of $23.7 \%$ in 19-year-olds and gradually decreases in older adults. ${ }^{13}$ Even though IMD incidence in developed countries has remained low during the last few years, mainly due to the implementation of universal infant vaccination, its epidemiology is often unpredictable and characterised by changes in incidence and prevalent serogroups. ${ }^{14}$ In Greece, the NIP includes MenC immunisation at 12 months of age since 2006 and MenACWY quadrivalent conjugated immunisation in 11 years old adolescents since 2012. Moreover, MenB vaccine has been available in the private market since 2014 but is not included in the NIP. ${ }^{7}$ Studies have already shown a decrease in the incidence of IMD during the COVID-19 pandemic. ${ }^{15-17}$

The non-pharmaceutical measures that have been used to contain the COVID-19 pandemic differ from country to country, while different age groups have been impacted in various ways. School closures, for example, have probably had a significant effect on the incidence of other infectious diseases in children. Taking into consideration the burden of both diseases on the paediatric population, ${ }^{5}{ }^{12}$ as well as the important role of this age group in community transmission, ${ }^{18}$ this study aimed to investigate the incidence of influenza and IMD in Greek children and adolescents aged 0-14 years during the COVID-19 pandemic.

\section{MATERIALS AND METHODS}

The surveillance of influenza in Greece is carried out using several systems. The Morbidity Monitoring System in Primary Healthcare (Sentinel) uses weekly reports from an established collaborating primary care unit network. Surveillance systems also include laboratory surveillance and surveillance of severe influenza cases in intensive care unit. Data are collected and published in the form of weekly reports by the National Public Health Organization (NPHO). These systems are active during the influenza surveillance period, from week 40 (October) of every year to week 20 (May) of the following year. Bacterial meningitis is a mandatory notifiable disease in Greece and all registered cases are investigated and classified by causative agent. IMD samples from hospitals nationwide are sent and identified at the National Meningitis Reference Laboratory. Confirmed cases are reported to NPHO.

For this population-based observational study, in collaboration with the NPHO, we collected data regarding weekly influenza-like illness (ILI) cases and annual influenza-related paediatric intensive care unit (PICU) admissions for influenza seasons 2014/2015-2020/2021 and monthly IMD cases from January 2014 until May 2021 among children aged $0-14$ years. The data were stratified by age group $(0-4,5-14$ years). To calculate incidence rates, we used the number of visits to the Sentinel Primary Healthcare units for children aged 0-14 years and each age group separately, as well as the population of children 0-14, 0-4 and 5-14 years old, according to the 2011 census data. Data from the COVID-19 pandemic period (2020-2021) were compared with that of the six preceding pre-COVID-period years (2014/2015-2019/2020). Influenza seasons and annual IMD cases were compared in total and by age group. Additional sensitivity analysis was performed to include IMD data from 2009, in order to examine the potential impact of the introduction of the Meningococcus serotype B vaccine in 2014.

Incidence rates were calculated for influenza as ILI cases per 1000 visits and influenza-related PICU admissions per 100000 population and for IMD as cases per 100000 population. Descriptive statistics of rates are presented with median and IQR. Percentage of decrease in the mean of annual rates over the two periods 20142020 versus 2021 was also calculated. Run charts were used to graphically represent the annual, monthly or weekly rates across time. Interrupted time series analysis was also performed to assess any changes in IMD trends. No statistical inference was made since the data used cover the study population. 


\section{0}

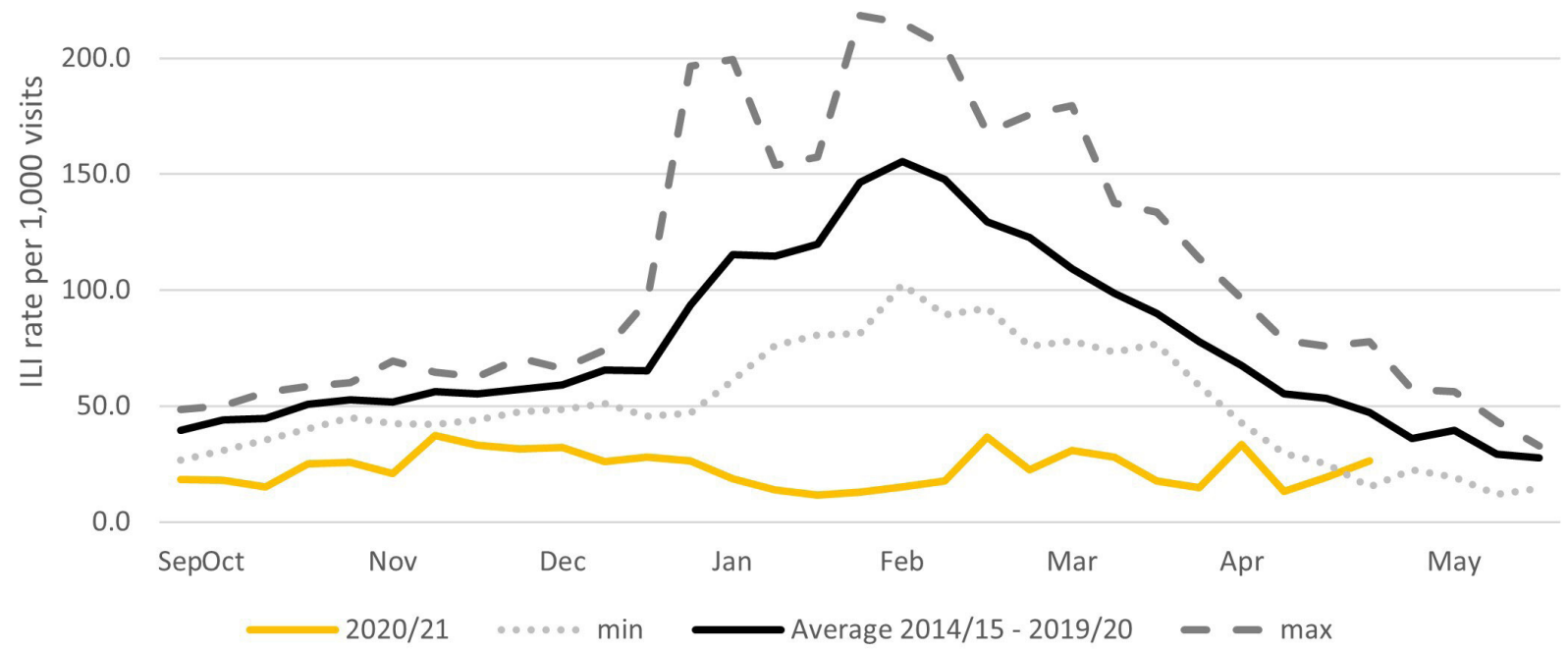

Figure 1 ILI weekly rates per 1000 visits during the influenza surveillance period 2020/2021 compared with minimum, mean and maximum of previous seasons (2014/2015-2019/2020) for children 0-14 years old. ILI, influenza-like illness.

Patient and public involvement

Authors declare that there was no patient or public involvement in the present study.

\section{RESULTS}

\section{Influenza}

The mean of weekly ILI rates per 1000 visits for children aged 0-14 years was notably lower during the season 2020/2021 compared with the preceding periods (2014/2015-2019/2020) (rates 88.2 vs 23.1, figure 1).

A reduction of $66.9 \%$ has been noted in the mean annual rate of ILI cases per 1000 visits among children younger than 14 years old, which has decreased from 102.9 during the pre-COVID-19 period (2014/2015$2019 / 2020)$ to 34.0 during $2020 / 2021$. The decrease in the mean annual rate was $58.5 \%$ and $71.8 \%$ for ages $0-4$ and 5-14, respectively (online supplemental figure S1).

Finally, no influenza-related PICU admissions were recorded in children aged 0-14 years during the period 2020/2021. The mean annual rate of laboratoryconfirmed influenza cases in PICU per 100000 population declined by $100 \%$, from 1.06 during the period 2014/2015-2019/2020 to 0.00 (figure 2).

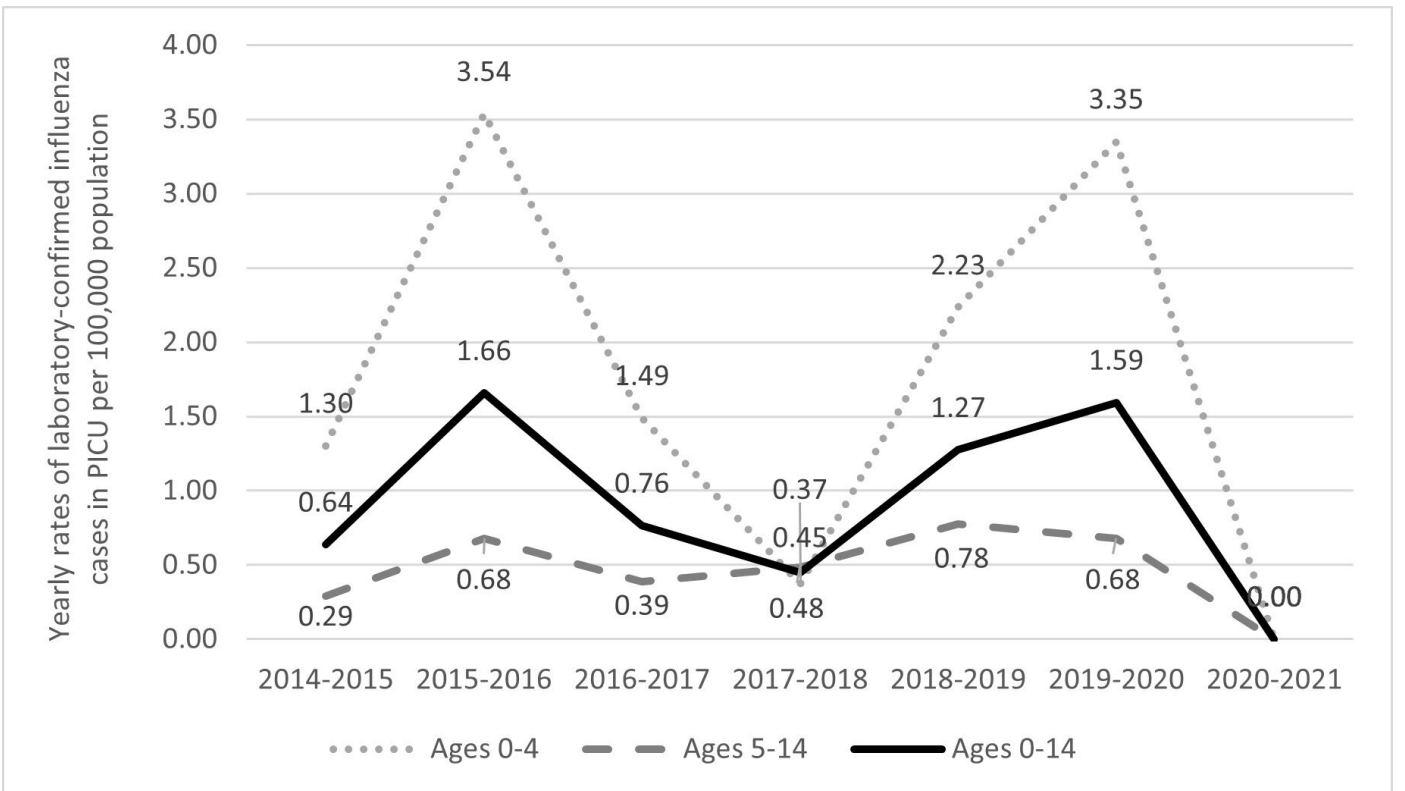

Figure 2 Annual rates of laboratory-confirmed influenza cases in PICU per 100000 population (2014/2015-2020/2021), stratified by age group. PICU, paediatric intensive care unit. 
Table 1 Summary statistics of monthly IMD rates per 100 000 population

\begin{tabular}{lll}
\hline Period & $\begin{array}{l}\text { Number } \\
\text { of } \\
\text { months }\end{array}$ & $\begin{array}{l}\text { Median of monthly } \\
\text { IMD rates per 100 000 } \\
\text { population (IQR) }\end{array}$ \\
\hline $\begin{array}{l}\text { Ages 0-14 } \\
\text { January 2014- } \\
\text { February 2020 }\end{array}$ & 73 & $0.10(0.05-0.15)$ \\
$\begin{array}{l}\text { March 2020-May } \\
\text { 2021 }\end{array}$ & 16 & $0.02(0.00-0.05)$ \\
$\begin{array}{l}\text { Ages 0-4 } \\
\text { January 2014- } \\
\text { February 2020 }\end{array}$ & 73 & $0.19(0.00-0.37)$ \\
$\begin{array}{l}\text { March 2020-May } \\
\text { 2021 }\end{array}$ & 16 & $0.00(0.00-0.19)$ \\
\hline $\begin{array}{l}\text { Ages 5-14 } \\
\text { January 2014- } \\
\text { February 2020 }\end{array}$ & 73 & $0.00(0.00-0.10)$ \\
\hline $\begin{array}{l}\text { March 2020-May } \\
\text { 2021 }\end{array}$ & 16 & $0.00(0.00-0.00)$ \\
\hline
\end{tabular}

IMD, invasive meningococcal disease .

\section{IMD}

The mean annual rate of IMD cases per 100000 children aged 0-14 during the period 2014-2019 was 1.38. A significant decrease of $70 \%$ was observed during 2020-2021 yielding a mean annual incidence of 0.41 . More specifically, the decrease in the mean annual rate was $67 \%$ and $76 \%$ for ages $0-4$ and 5-14, respectively (online supplemental figure $\mathrm{S} 2$ ).

Descriptive statistics of monthly IMD rates per 100000 population are presented in table 1 . The median of monthly incidence rates of the period March 2020-May 2021 was 0.02 , which is considerably lower than the one of the period from January 2014 to February 2020 (0.10). IMD monthly rates during the period 2020-2021 compared with the mean monthly rates of the years 2014-2019 are shown in figure 3. On applying interrupted time series analysis there was no change in the trend between the periods 2014-2019 and 2020-2021. In order to examine the potential impact of MenB immunisation after 2014, the analysis was repeated using data from 2009. A consistent trend of decrease was observed throughout the examined period, with no significant trend change (figure 4).

\section{DISCUSSION}

Influenza and IMD represent important vaccinepreventable diseases with a high disease burden in children aged under 15 years. ${ }^{19}$ The incidence of both diseases has shown notable reduction, mainly among adults so far, following the implementation of COVID-19 restrictions, not only in Europe but also worldwide. ${ }^{7-915-17}$ In this study, a significant decline was observed in the number of recorded ILI and influenza-related PICU cases, as well as confirmed IMD cases among children 0-14 years old during the period 2020-2021 compared with previous years (2014-2019). As in many countries, influenza remained at an all-time low in Greece during the period 2020/2021, while no circulation of influenza was detected this past winter. A considerable decrease was also observed in the incidence of IMD since March 2020, although there was no significant change in the trend. IMD cases in Greece have been steadily declining since 2013, coinciding with the introduction of the MenB vaccine in March 2014. Interestingly, the number of MenB vaccinations has also declined since March 2020 (data not shown), suggesting that they might not have contributed to the excess reduction of IMD cases during

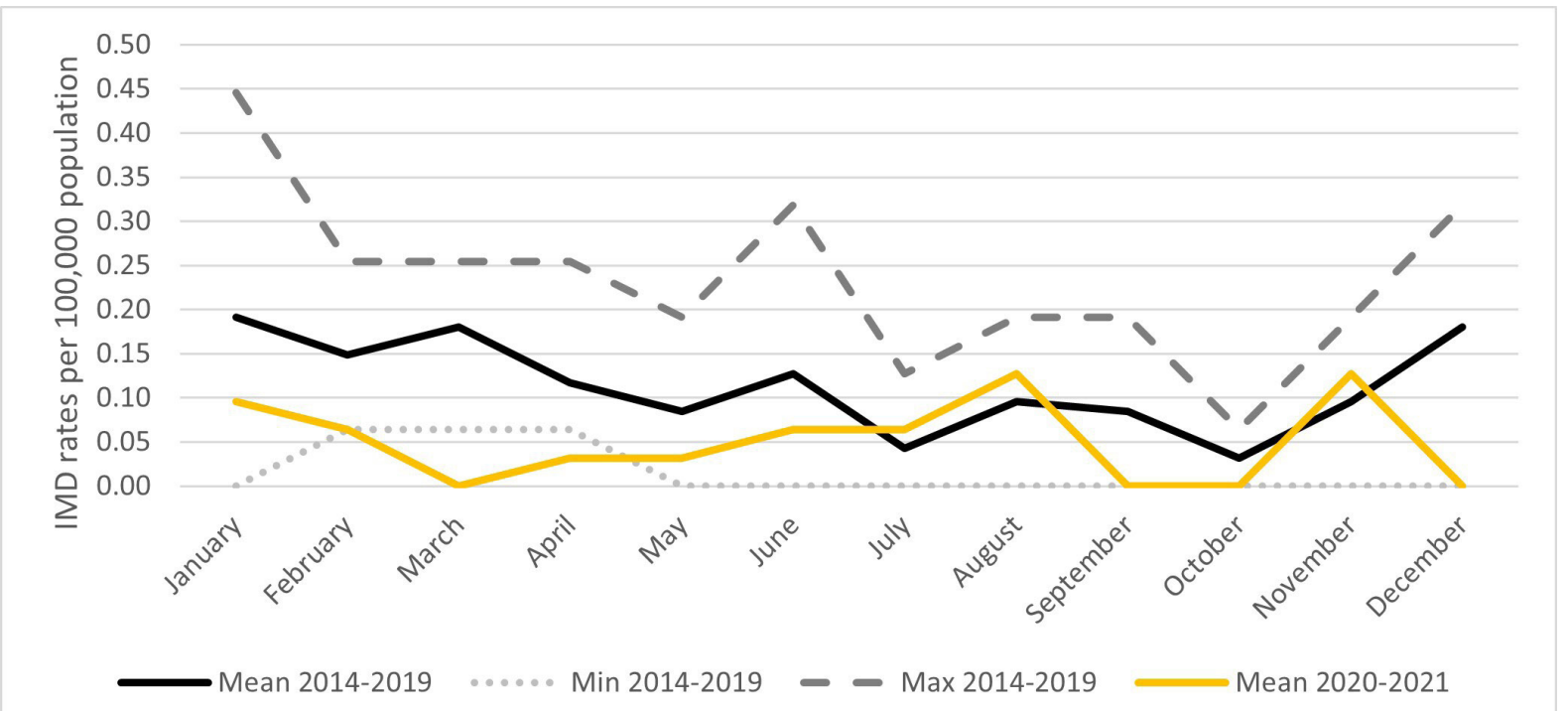

Figure 3 IMD monthly rates per 100000 children aged 0-14 years during the period 2020-2021 compared with minimum, mean and maximum of previous seasons (2014-2019). IMD, invasive meningococcal disease. 


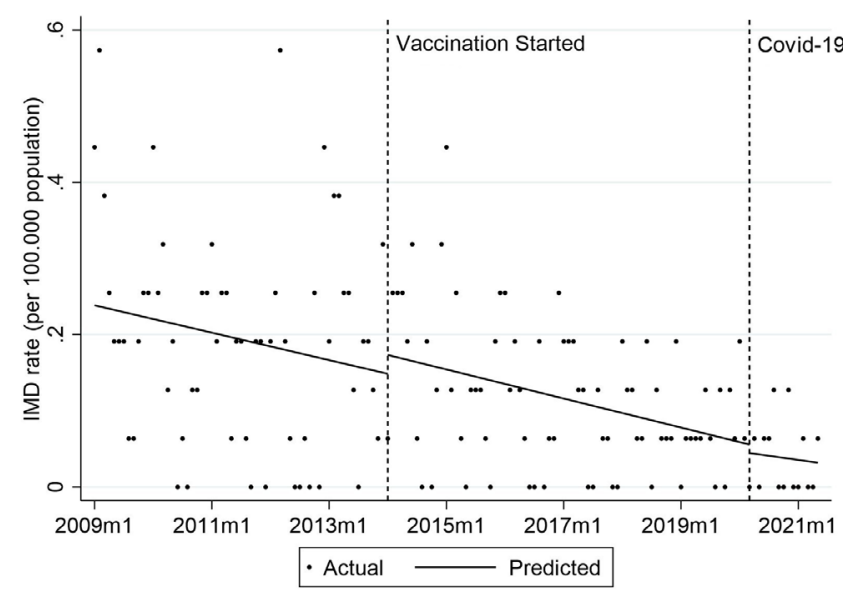

Figure 4 Monthly IMD rates per 100000 population for ages $0-14$, interrupted by vaccination programme (January 2014) and COVID-19 pandemic (March 2020). IMD, invasive meningococcal disease.

the period 2020-2021. A recent study in France showed that the observed decrease of IMD during lockdown mainly involved the highly transmissible and hyperinvasive isolates, indicating decreased direct transmission between subjects. ${ }^{16}$

Measures used to reduce the transmission of an airborne agent are expected to decrease the circulation of other respiratory pathogens. The decline in the incidence of influenza and IMD did indeed coincide with the implementation of non-pharmaceutical interventions (NPIs) that aimed to mitigate SARS-CoV-2 transmission. Governmental strategy regarding those interventions in Greece, has been changing during the past 18 months of the pandemic based on the epidemiological data. School closures were first announced in March 2020 and distance learning remained for the most part of 2021, possibly contributing to the reduction of influenza and IMD circulation among children. Since school-aged children play a key role in the transmission of seasonal influenza, ${ }^{18}$ this reduction probably also affected its incidence in adults. Other measures that might also have contributed to the decreased incidence of both diseases in children include mask wearing, parental teleworking, physical distancing, travel restrictions and limitation of social gatherings. The lower basic reproduction number $\left(\mathrm{R}_{0}\right)$ of influenza ${ }^{20}$ and $\mathrm{IMD}^{21}$ compared with that of SARS-CoV-2, is a possible explanation for the much stronger impact that those measures had on their transmission. Few recent studies have shown a decrease in multiple respiratory agents. ${ }^{22-26}$ Interestingly, a case series study, that investigated hospitalisation rates of children under the age of 2 years due to lower respiratory infections, revealed a significant reduction in hospitalisation mainly caused by enveloped viruses. Incidence of unenveloped viruses such as rhinoviruses/enteroviruses did not show such impressive decrease. $^{26}$
Another contributing factor to the observed decline of the number of influenza cases could be the reduction of healthcare utilisation. ${ }^{27}$ The number of visits of both age groups reported by the Sentinel surveillance system has in fact decreased during the period 2020/2021. However, the ILI rates per 1000 visits have also declined notably, showing that the decreased number of reported cases reflects an actual lack of infections. As far as IMD is concerned, due to the severity of the disease, healthcareseeking behaviour is unlikely to be affected by the pandemic.

The possibility of an influenza pandemic, ${ }^{28}$ as well as the unpredictable epidemiology of IMD,${ }^{14}$ highlight the importance of these findings. Given the concerns that the influenza season would coincide with the pandemic or that COVID-19-like other viral infections-could be linked with an increase in IMD cases, the reduced incidence of both diseases has been reassuring. However, due to the low circulation of respiratory pathogens, population susceptibility has possibly increased over the past months and thus some researchers predict large outbreaks in the near future with possible shift of the usual seasonality of viral infections. ${ }^{29}{ }^{30}$ This becomes more evident by the unexpected resurgence of Respiratory Syncytial Virus (RSV) after its initial decline during the COVID-19 pandemic. ${ }^{30-33}$ The upcoming 2021-2022 endemic period remains unknown and will possibly be influenced by the burden of COVID-19 and the extent of NPI use. Nonetheless, influenza immunisation is highly recommended this coming autumn in the Northern hemisphere. Although the very low previous influenza season in 2020-2021 may have impacted the identification of emerging circulating strains endangering the influenza vaccine effectiveness, it is important to stress that vaccination is the most effective way to reduce the influenza-related disease burden. ${ }^{34}$ At the same time, the knowledge gained by the COVID-19 pandemic regarding the value of specific NPIs in the control of respiratory pathogens' transmission is a powerful tool for future prevention and management of both influenza and IMD, especially for high-risk populations.

A strength of this study is that the data used were derived from a nationwide surveillance system that existed before the emergence of COVID-19, allowing reliable comparisons between the different periods. Furthermore, our study focuses on the impact that COVID-19 restrictions had on the incidence of influenza and IMD specifically in the paediatric population, which is particularly affected by both diseases, in terms of transmission as well as morbidity.

However, there are several limitations that need to be acknowledged. There is lack of data regarding laboratoryconfirmed influenza cases and consequently information on prevalent types and subtypes. Laboratory surveillance data of influenza in Greece are collected solely by the two National Reference Laboratories, which are not necessarily representative of the total number of influenza tests that are conducted. Secondly, due to the ecological 
nature of this study, causality between the interventions and the decreased incidence of the two diseases cannot be determined. However, temporal association and biological plausibility make it a compelling hypothesis. Finally, the Sentinel data used in this study were based on clinicians' reports. It is, therefore, possible that the number of influenza cases is underestimated due to lower disease reporting rates during the pandemic.

To conclude, maintaining the wide use of NPIs has shown to be effective in mitigating the transmission of respiratory agents in the community. Nevertheless, the dynamics of infectious diseases remain ever-changing and it is vital that we remain vigilant. Therefore, ongoing surveillance, as well as vaccinations, are of great importance in order to reduce the burden of influenza and IMD on the already overwhelmed healthcare systems.

\section{Author affiliations}

${ }^{1}$ Third Department of Pediatrics, Attikon University Hospital, National and Kapodistrian University of Athens, Athens, Attica, Greece

${ }^{2}$ Centre for Clinical Epidemiology and Outcomes Research (CLE0), Athens, Greece

${ }^{3}$ Department of Healthcare-Associated Infections and Antimicrobial Resistance, Directorate of Epidemiological Surveillance and Intervention for Infectious Diseases, National Public Health Organization, Athens, Greece

${ }^{4}$ Department of Surveillance Systems, Directorate of Epidemiological Surveillance and Interventions for Infectious Diseases, National Public Health Organization, Athens, Greece

${ }^{5}$ Department of Respiratory Diseases, Directorate of Epidemiological Surveillance and Interventions for Infectious Diseases, National Public Health Organization, Athens, Greece

${ }^{6}$ Department for Vaccine Preventable Diseases and Congenital Diseases, Directorate of Epidemiological Surveillance and Interventions for Infectious Diseases, National Public Health Organization, Athens, Greece

${ }^{7}$ National Meningitis Reference Laboratory, Department of Public Health Policy, University of West Attica, Athens, Greece

${ }^{8}$ Second Department of Pediatrics, P\&A Kyriakou Children's Hospital, National and Kapodistrian University of Athens, Athens, Attica, Greece

${ }^{9}$ National Public Health Organization, Athens, Greece

Acknowledgements We would like to thank Panagiotis Katerelos for editing and organising the influenza Sentinel data and Dimitra Koussi for assisting in the statistical analysis.

Contributors DK participated in the conceptualisation and design of the study; contributed to data interpretation and writing, reviewing and editing of the manuscript. EK participated in the statistical analysis; contributed to the interpretation of the analysis and reviewing and editing of the manuscript. FK, KG, $\mathrm{KP}, \mathrm{TG}, \mathrm{IM}, \mathrm{AA}$ and GT participated in the acquisition and interpretation of data; contributed to reviewing and editing of the manuscript. TZ participated in the conceptualisation and design of the study; contributed to the interpretation of the statistical analysis and reviewing and editing of the manuscript. VP is the guarantor for this study and participated in the conceptualisation and design, supervision and project administration; contributed to data interpretation and writing, reviewing and editing of the manuscript.

Funding The authors have not declared a specific grant for this research from any funding agency in the public, commercial or not-for-profit sectors.

Competing interests None declared.

Patient consent for publication Not applicable.

Ethics approval This study does not involve human participants.

Provenance and peer review Not commissioned; externally peer reviewed.

Data availability statement Data are available upon reasonable request. Aggregate data may be available on request to the corresponding author and after approval by the NPHO.
Supplemental material This content has been supplied by the author(s). It has not been vetted by BMJ Publishing Group Limited (BMJ) and may not have been peer-reviewed. Any opinions or recommendations discussed are solely those of the author(s) and are not endorsed by BMJ. BMJ disclaims all liability and responsibility arising from any reliance placed on the content. Where the content includes any translated material, BMJ does not warrant the accuracy and reliability of the translations (including but not limited to local regulations, clinical guidelines, terminology, drug names and drug dosages), and is not responsible for any error and/or omissions arising from translation and adaptation or otherwise.

Open access This is an open access article distributed in accordance with the Creative Commons Attribution Non Commercial (CC BY-NC 4.0) license, which permits others to distribute, remix, adapt, build upon this work non-commercially, and license their derivative works on different terms, provided the original work is properly cited, appropriate credit is given, any changes made indicated, and the use is non-commercial. See: http://creativecommons.org/licenses/by-nc/4.0/.

ORCID iD

Danai Ktena http://orcid.org/0000-0002-0952-8915

\section{REFERENCES}

1 Tan W, Zhao X, Ma X, et al. A novel Coronavirus Genome Identified in a Cluster of Pneumonia Cases - Wuhan, China 2019-2020. China CDC Wkly 2020;2:61-2.

2 WHO Director-General's opening remarks at the media briefing on COVID-19, 2020. Available: https://www.who.int/director-general/ speeches/detail/who-director-general-s-opening-remarks-at-themedia-briefing-on-covid-19-11-march-2020 [Accessed 19 Dec 2021].

3 WHO Coronavirus (COVID-19) Dashboard. Available: https:// covid19.who.int/ [Accessed 19 Dec 2021].

4 Umakanthan S, Sahu P, Ranade AV, et al. Origin, transmission, diagnosis and management of coronavirus disease 2019 (COVID-19). Postgrad Med J 2020;96:753-8.

5 Neuzil KM, Mellen BG, Wright PF, et al. The effect of influenza on hospitalizations, outpatient visits, and courses of antibiotics in children. N Engl J Med 2000;342:225-31.

6 Shaman J, Kohn M. Absolute humidity modulates influenza survival, transmission, and seasonality. Proc Natl Acad Sci U S A 2009;106:3243-8.

7 National Immunization Program for children and adolescents, 2020. Available: https://www.moh.gov.gr/articles/health/dieythynshdhmosias-ygieinhs/emboliasmoi/ethniko-programma-emboliasmwnepe-paidiwn-kai-efhbwn/7246-programma-emboliasmwn-paidiwnefhbwn-2020 [Accessed 23 cited 2021].

8 Adlhoch C, Mook P, Lamb F. European influenza surveillance network. very little influenza in the who European region during the 2020/21 season, weeks 402020 to 82021 . Euro Surveill 2021;26:2100221.

9 Olsen SJ, Azziz-Baumgartner E, Budd AP, et al. Decreased Influenza Activity During the COVID-19 Pandemic - United States, Australia, Chile, and South Africa, 2020. MMWR Morb Mortal Wkly Rep 2020;69:1305-9.

10 Sullivan SG, Carlson S, Cheng AC, et al. Where has all the influenza gone? the impact of COVID-19 on the circulation of influenza and other respiratory viruses, Australia, March to September 2020. Euro Surveill 2020;25:2001847.

11 Salomon A, Berry I, Tuite AR, et al. Influenza increases invasive meningococcal disease risk in temperate countries. Clin Microbiol Infect 2020;26:1257.e1-1257.e7.

12 Rouphael NG, Stephens DS. Neisseria meningitidis: biology, microbiology, and epidemiology. Methods Mol Biol 2012;799:1-20.

13 Christensen H, May M, Bowen L, et al. Meningococcal carriage by age: a systematic review and meta-analysis. Lancet Infect Dis 2010;10:853-61.

14 Chang Q, Tzeng Y-L, Stephens DS. Meningococcal disease: changes in epidemiology and prevention. Clin Epidemiol 2012;4:237-45

15 Brueggemann AB, Jansen van Rensburg MJ, Shaw D, et al. Changes in the incidence of invasive disease due to Streptococcus pneumoniae, Haemophilus influenzae, and Neisseria meningitidis during the COVID-19 pandemic in 26 countries and territories in the invasive respiratory infection surveillance initiative: a prospective analysis of surveillance data. Lancet Digit Health 2021;3:e360-70.

16 Taha M-K, Deghmane A-E. Impact of COVID-19 pandemic and the lockdown on invasive meningococcal disease. BMC Res Notes 2020;13:399. 
17 Subbarao S, Campbell H, Ribeiro S, et al. Invasive meningococcal disease, 2011-2020, and impact of the COVID-19 pandemic, England. Emerg Infect Dis 2021;27:2495-7.

18 Brownstein JS, Kleinman KP, Mandl KD. Identifying pediatric age groups for influenza vaccination using a real-time regional surveillance system. Am J Epidemiol 2005;162:686-93.

19 Cassini A, Colzani E, Pini A, et al. Impact of infectious diseases on population health using incidence-based disability-adjusted life years (DALYs): results from the burden of communicable diseases in Europe study, European Union and European economic area countries, 2009 to 2013. Euro Surveill 2018;23:17-454.

20 Petersen E, Koopmans M, Go U, et al. Comparing SARS-CoV-2 with SARS-CoV and influenza pandemics. Lancet Infect Dis 2020;20:e238-44.

21 Trotter CL, Gay NJ, Edmunds WJ. Dynamic models of meningococcal carriage, disease, and the impact of serogroup $\mathrm{C}$ conjugate vaccination. Am J Epidemiol 2005;162:89-100.

22 Kitano $T$. The estimated burden of 15 vaccine-preventable diseases from 2008 to 2020 in Japan: a transition by the COVID-19 pandemic $J$ Infect Chemother 2021;27:1482-8.

23 Groves HE, Piché-Renaud P-P, Peci A, et al. The impact of the COVID-19 pandemic on influenza, respiratory syncytial virus, and other seasonal respiratory virus circulation in Canada: a populationbased study. Lancet Reg Health Am 2021;1:100015

24 Park JY, Kim HI, Kim J-H, et al. Changes in respiratory virus infection trends during the COVID-19 pandemic in South Korea: the effectiveness of public health measures. Korean J Intern Med 2021;36:1157-68.
25 Kaur R, Schulz S, Fuji N, et al. COVID-19 pandemic impact on respiratory infectious diseases in primary care practice in children. Front Pediatr 2021;9:722483.

26 Ippolito G, La Vecchia A, Umbrello G, et al. Disappearance of seasonal respiratory viruses in children under two years old during COVID-19 pandemic: a monocentric retrospective study in Milan, Italy. Front Pediatr 2021;9:721005.

27 Moynihan R, Sanders S, Michaleff ZA, et al. Impact of COVID-19 pandemic on utilisation of healthcare services: a systematic review. BMJ Open 2021;11:e045343.

28 Laver WG, Bischofberger N, Webster RG. The origin and control of pandemic influenza. Perspect Biol Med 2000;43:173-92.

29 Baker RE, Park SW, Yang W, et al. The impact of COVID-19 nonpharmaceutical interventions on the future dynamics of endemic infections. Proc Natl Acad Sci U S A 2020;117:30547-53.

30 Weinberger Opek M, Yeshayahu Y, Glatman-Freedman A, et al. Delayed respiratory syncytial virus epidemic in children after relaxation of COVID-19 physical distancing measures, Ashdod, Israel, 2021. Euro Surveill 2021;26:2100706.

31 Agha R, Avner JR. Delayed seasonal RSV surge observed during the COVID-19 pandemic. Pediatrics 2021;148:e2021052089.

32 Foley DA, Yeoh DK, Minney-Smith CA, et al. The Interseasonal resurgence of respiratory syncytial virus in Australian children following the reduction of coronavirus disease 2019-Related public health measures. Clin Infect Dis 2021;73:e2829-30.

33 Hussain F, Kotecha S, Edwards MO. RSV bronchiolitis season 2021 has arrived, so be prepared! Arch Dis Child 2021;106:e51.

34 Kramer SC, Bansal S. Assessing the use of antiviral treatment to control influenza. Epidemiol Infect 2015;143:1621-31. 